\title{
Sialendoscopy for salivary stones: principles, technical skills and therapeutic experience
}

\author{
Il ruolo della scialoendoscopia nel trattamento delle litiasi salivari: principi di base, \\ aspetti tecnici ed esperienza clinica \\ F. CARTA ${ }^{1}$, P. FARNETI2, S.CANTORE², G. MACRì ${ }^{2}$, N. CHUCHUEVA ${ }^{13}$, L. CUFFARO ${ }^{1}$, E. PASQUINI ${ }^{4}$, \\ R. PUXEDDU ${ }^{1}$ \\ ' Department of Otorhinolaryngology, University of Cagliari, Azienda Ospedaliero Universitaria di Cagliari, Italy; \\ ${ }^{2}$ Ear, Nose and Throat Unit of Sant'Orsola-Malpighi Hospital, Bologna, Italy; ${ }^{3}$ I.M. Sechenov First Moscow State \\ Medical University, 11991, Moscow, Russia; ${ }^{4}$ Ear, Nose and Throat Metropolitan Unit - Surgical Department - AUSL \\ Bologna, Bellaria Hospital, Bologna, Italy \\ All the authors contributed equally to the manuscript
}

\begin{abstract}
SUMMARY
Obstructive sialadenitis is the most common non-neoplastic disease of the salivary glands, and sialendoscopy is increasingly used in both diagnosis and treatment, associated in selected cases with endoscopic laser lithotripsy. Sialendoscopy is also used for combined minimally invasive external and endoscopic approaches in patients with larger and proximal stones that would require excessively long laser procedures. The present paper reports on the technical experience from the Ear, Nose and Throat Unit of the Sant'Orsola-Malpighi Hospital of Bologna, and from the Department of Otorhinolaryngology of the University Hospital of Cagliari, Italy, including the retrospective analysis of the endoscopic and endoscopic assisted procedures performed on 48 patients (26 females and 22 males; median age 45.3; range 8-83 years) treated for chronic obstructive sialadenitis at the University Hospital of Cagliari from November 2010 to April 2016. The results from the Sant'Orsola-Malpighi Hospital of Bologna have been previously published. The technical aspects of sialendoscopy are carefully described. The retrospective analysis of the University Hospital of Cagliari shows that the disease was unilateral in 40 patients and bilateral in 8; a total of 56 major salivary glands were treated (22 submandibular glands and 34 parotids). Five patients underwent bilateral sialendoscopy for juvenile recurrent parotitis. 10 patients were treated for non-lithiasic obstructive disease. In 33 patients (68.75\%) the obstruction was caused by salivary stones (bilateral parotid lithiasis in 1 case). Only 8 patients needed a sialectomy (5 submandibular glands and 3 parotids). The conservative approach to obstructive sialadenitis is feasible and can be performed either purely endoscopically or in a combined modality, with a high percentage of success. The procedure must be performed with dedicated instrumentation by a skilled surgeon after proper training since minor to major complications can be encountered. Sialectomy should be the "extrema ratio" after failure of a conservative approach.
\end{abstract}

KEY WORDS: Sialendoscopy $\bullet$ Obstructive sialadenitis $\bullet$ Salivary glands $\bullet$ Lithiasis

\section{RIASSUNTO}

La scialoadenite cronica ostruttiva rappresenta una delle più frequenti patologie non-neoplastiche delle ghiandole salivari e la scialoendoscopia è sempre più utilizzata nella sua diagnosi e nel suo trattamento, associata o meno con la litotripsia laser. La scialoendoscopia può essere inoltre associata ad approcci esterni mini-invasivi nelle litiasi troppo voluminose per essere rimosse con un approccio unicamente endoscopico. Il presente articolo riporta l'esperienza delle Cliniche Otorinolaringoiatriche dell'Ospedale Sant'Orsola-Malpighi di Bologna e dell'Azienda Ospedaliero Universitaria di Cagliari, Italia. È stata eseguita un'analisi retrospettiva su 48 pazienti (26 femmine, 22 maschi; età media di 45,3 anni; range 8-83 anni) trattati per patologia cronica ostruttiva delle ghiandole salivari maggiori mediante procedure chirurgiche endoscopiche o combinate da novembre 2010 ad aprile 2016 presso l'Azienda-Ospedaliero-Universitaria di Cagliari. I risultati dell'Ospedale Sant'Orsola-Malpighi di Bologna erano stati precedentemente pubblicati. Gli aspetti tecnici della scialoendoscopia sono stati accuratamente descritti. I pazienti trattati presso l'Azienda Ospedaliero Universitaria di Cagliari presentavano una patologia unilaterale in 40 casi e bilaterale in 8 casi; sono state trattate 56 ghiandole salivari maggiori (22 sottomandibolari e 34 parotidi). 5 pazienti sono stati sottoposti a scialoendoscopia bilaterale per parotite ricorrente giovanile, 10 per patologia ostruttiva non litiasica e $33(68,75 \%)$ presentavano calcoli salivari (1 paziente presentava una litiasi parotidea bilaterale). Solo 8 pazienti sono stati sottoposti a scialectomia radicale per via esterna (5 scialectomie sottomandibolare e 3 parotidectomie). La chirurgia conservativa nei pazienti con scialoadenite cronica ostruttiva appare efficace e può essere realizzata mediante un approccio puramente endoscopico o combinato, con un'alta percentuale di successo. La procedura richiede una strumentazione adeguata e deve essere eseguita da un chirurgo esperto, che abbia svolto un training specifico scialoendoscopico, in modo da evitare le possibili complicanze maggiori e minori. La scialectomia tradizionale rappresenta la "extrema ratio", limitata nei casi in cui un approccio conservativo sia risultato inefficace o controindicato.

PAROLE CHIAVE: Scialoendoscopia $\bullet$ Scialoadenite ostruttiva $\bullet$ Ghiandole salivari $\bullet$ Litiasi 


\section{Introduction}

Obstructive sialadenitis is the most common non-neoplastic disease of the salivary glands ${ }^{1}$. Salivary stones are one of the main causes of chronic sialadenitis, and account for approximately $50 \%$ of major salivary gland diseases. Most salivary calculi (80\%-95\%) occur in the submandibular gland, whereas 5\%-20\% are found in the parotid gland, while the sublingual gland and the minor salivary glands account for no more than $2 \%{ }^{1}$. Other aetiologies of salivary duct obstruction include strictures, mucoid debris, anatomic ductal abnormalities and scar tissue ${ }^{2}$. Initial treatment of obstructive sialadenitis is usually conservative with hydration, salivary flow stimulation, antiinflammatory medication and antibiotics when bacterial infection is suspected. However, when initial treatment fails, further intervention is needed. The classic external approach is sialectomy with a potential incidence of injuries to the lingual and facial nerves, as well as complications such as bleeding, infection and scar ${ }^{34}$. The management of salivary obstruction has changed dramatically over the past 20 years ${ }^{5}$. Flexible endoscopes, thin enough to be introduced into the salivary pathway were proposed for the first time by Katz ${ }^{67}$; subsequently, the introduction of micro-instruments allowed for conservative minimally invasive treatment of salivary gland diseases like the removal of granulation tissue, dilatation of stenotic ducts and retrieval of stones with forceps or basket ${ }^{8}$. At the beginning, stones of more than $4 \mathrm{~mm}$ in diameter represented the boundaries of an endoscopic approach, but the association with extracorporeal or intracorporeal lithotripsy allowed the removal of bigger stones ${ }^{9}{ }^{10}$. Nowadays, sialendoscopy is considered a beneficial technique since it is less invasive, has a lower morbidity rate compared to other techniques ${ }^{11}$, and can also be combined with minimal external approaches ${ }^{12}$. Combined endoscopic and external approaches can also be performed with operative microscope and intraoperative nerve monitoring (NIM) systems to reduce complications. Sialendoscopy requires a high level of dedicated experience, especially if balloon dilatation or laser lithotripsy is carried out; as a consequence, proper training is highly recommended.

The present paper will review all available sialendoscopic instrumentation and techniques, and analyses the potential results attainable in diagnostic and therapeutic sialendoscopy.

\section{Materials and methods}

The present paper is based on the technical experience from the Ear, Nose and Throat Unit of the Sant'Orsola-Malpighi Hospital in Bologna, and from the Department of Otorhinolaryngology of the University Hospital of Cagliari, Italy, including the retrospective analysis of the endoscopic and endoscopic assisted procedures per- formed on 48 patients treated for chronic obstructive sialadenitis at the University Hospital of Cagliari, Italy, from November 2010 to April 2016. Patients of our early series who underwent extracorporeal lithotripsy, and those who were treated for submandibular lithiasis by a combined endoscopic and intraoral procedure with marsupialization of the duct were not considered in the present article. The results of the Sant'Orsola-Malpighi Hospital of Bologna, Italy, have been already published by Farneti et al ${ }^{13}$.

Data collected included details of patients, clinical presentation, management and outcomes.

All adult patients underwent computed tomography (CT) or magnetic resonance imaging (MRI) whereas children underwent ultrasound (US) or MRI. Sialendoscopy was always performed in patients with unclear obstructive sialadenitis, but when ductal disease was identified, such as mucous plugs, strictures or granulation tissue, sialendoscopy was converted in interventional by using sialendoscopes with operative channel, forceps, balloons, or baskets. Stones between 2 and $15 \mathrm{~mm}$, and those that were impossible to retrieve using a wire basket or grasping forceps were fragmented before the endoscopic removal with intraoperative lithotripsy or removed with a combined approach.

The endoscopic approach to the salivary glands requires specific instrumentation classified in several categories: Karl Storz ${ }^{\circledR}$ and Fentex ${ }^{\circledR}$ semi-rigid sialendoscopes with a direct view at $0^{\circ}$. Flexible endoscopes are advantageous as it is possible to move them through ductal kinks and bends. Their use is usually atraumatic, but handling can be difficult. They are fragile, have a short lifespan and are not autoclavable ${ }^{14}$. Rigid endoscopes use a pure lens system with good optical quality and better resolution. These endoscopes have larger diameters but are more stable, and can be autoclaved. The camera is fixed directly onto the ocular attached to the endoscope, resulting in a cumbersome handling ${ }^{14}$. Semi-rigid endoscopes are a compromise between flexible and rigid instruments ${ }^{14}$ and actually represent the gold standard for sialendoscopy. Handling is easier and image quality is good. Modular and compact types are available. In modular endoscopes, the optical fibres used for light and image transmission are combined into a single probe-like component. This can be used in combination with different sheaths ${ }^{14}$. Compact "all-in-one" endoscopes combine a fibre light transmission, a fibre image transmission, a working channel and an irrigation channel within one instrument (Fig. 1a). The outer tube covers, stabilises and protects all of the components, resulting in a minimum outer diameter of the whole system. The outer diameter is of paramount importance for the introduction of the scopes and its advancement inside the narrow ductal system. There are two types of compact endoscopes: the diagnostic sialendoscope with only an irrigation channel of $0.25 \mathrm{~mm}$ and an outer diameter of $0.9 \mathrm{~mm}$, generally used for primary explora- 


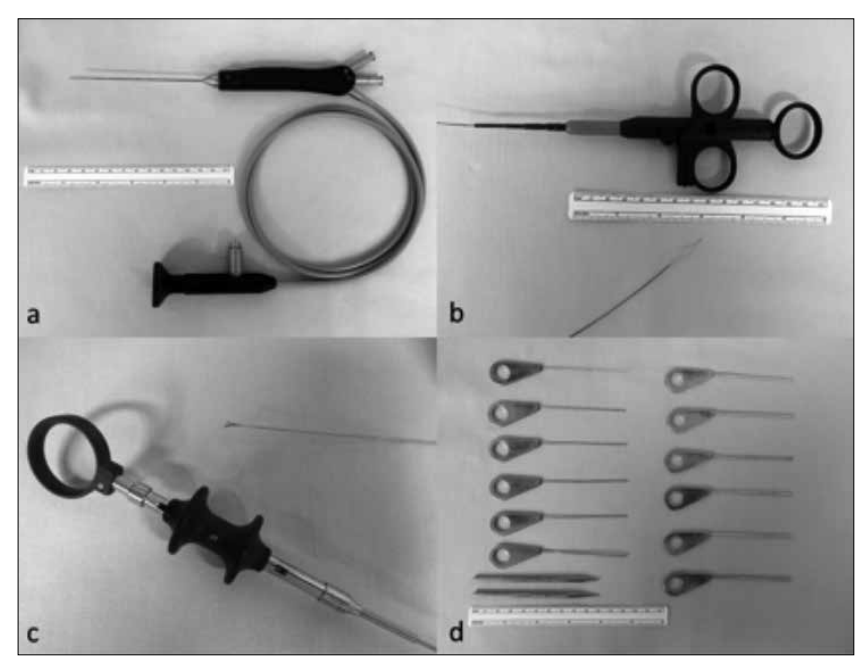

Fig. 1. Sialendoscopic instruments. a: Compact semi-rigid endoscope with $0.4 \mathrm{~mm}$ working channel. b: Four wire basket. c: Forceps. d: Progressive salivary probe and conic dilatator.

tion especially in paediatric ducts or fibrous or stenotic ducts, and the operative sialendoscope, a double-lumen device with a working channel for the insertion of dedicated tools (i.e. baskets, forceps, balloons and/or laser fibres) that allows therapeutic tasks ${ }^{14}{ }^{15}$. The operative endoscopes are manufactured with outer diameters of 1.1 and $1.6 \mathrm{~mm}$ and operative channels of 0.4 and $0.8 \mathrm{~mm}$, respectively. The $0.4 \mathrm{~mm}$ working channel allows passage of the basket and laser probe or micro burr, while for other instruments like grasping forceps or biopsy forceps the $0.6 \mathrm{~mm}$ diameter is needed. To maintain the best optical quality of the endoscope, it is important to add a full high definition (HD) system. This permits to obtain higher image resolution with better details and depth of focus using filters. The camera is always correctly oriented with the endoscope in order to handle it efficiently. The Dormia baskets, which are composed of four or more wires, are used for removing stones, mucous plugs and foreign bodies; this device is activated by the surgeon. The endoluminal object must be mobile and, when captured, the surgeon can pull it out. Baskets are currently available in different sizes and the more frequent outer diameter is 0.4 $\mathrm{mm}$ (Fig. 1b). Forceps measuring $0.8 \mathrm{~mm}$ of diameter are available in two different shapes: grasping forceps with a serrated surface on the jaws, and biopsy cup forceps with sharp cutting edges that could also be used for stone fragmentation and removal (Fig. 1c) ${ }^{14}$. Drills or micro burrs have diameters from 0.38 to $0.4 \mathrm{~mm}$. They could be used for stone fragmentation and dilatation of filiform or complete stenosis. An electrically powered motor system and shifter system can be especially helpful for hard stones ${ }^{14}$. In some patients, the identification of the papilla required the aid of an operative microscope (Carl Zeiss ${ }^{\circledR}$, Germany, Microscope ZEISS S7 - focal length $250 \mathrm{~mm}$ ). The papilla can be dilated using a set of commercially available probes in 12 sizes of increasing diameter (from 0000 to 8 as shown in Fig. 1d) (Karl Storz ${ }^{\circledR}$, Germany). They can be particularly useful in cases of a narrow papilla, but these instruments can easily cause a ductal perforation or a false path. Conic dilator (length 10-14 cm) should be used instead of a salivary probe for gentle dilation of the papilla with a lower risk of a ductal perforation. In the present series, papillotomy was performed in the earlier cases, and was then converted in a dilatation or by the incision of the duct proximal to the papilla in the submandibular gland. For the parotid, the papilla was always dilated. Low-pressure and high-pressure balloons are available. The former have only limited efficacy, mainly for thin membrane-like strictures, and have a high risk of rupturing. The second require a special syringe system for inflation and can be used for dilatation of lesions and strictures in the submandibular (Fig. 2) and parotid salivary ducts ${ }^{14}$. Patients with strictures were also treated without complications with the aid of an expandable off-label compliant balloon angiocatheter (Boston Scientific ${ }^{\circledR}$ ) or a Lacrycath off labels non-compliant balloon (QuestFigMedical ${ }^{\circledR}$, U.S.A.), 5 $\mathrm{mm}$ in diameter, after obtaining consent from the patient. In the present series, the holmium:YAG (yttrium-aluminium-garnet) laser has been routinely used for endoscopic lithotripsy. This is a pulsed, solid-state laser that produces light at a wavelength of $2.1 \mu \mathrm{m}$ in the near-infrared region. It also has a high absorption coefficient in water, suggesting a safety advantage if used in an aqueous environment such as saliva. It creates a shock-wave when the laser is activated and the tip of the fibre is placed perpendicular to the surface of the stone. Lithotripsy is then carried on by a cavitation technique until the stone is completely fragmented ${ }^{9}$. The semi-flexible fibre with diameter of 200 or $365 \mu \mathrm{m}$ holmium:YAG laser (Lumenis ${ }^{\circledR}$, Israel) was used with a power of $2.5 \mathrm{~W}-3.5 \mathrm{~W}$, a rate of $5 \mathrm{~Hz} / \mathrm{s}$, and energy of $0.5 \mathrm{~J}-0.7 \mathrm{~J}$. Laser lithotripsy was always planned under general anaesthesia. This laser is a non dedicated tool.

Sialendoscopy was also performed using the Image1 S System ${ }^{\mathrm{TM}}$ (Storz, Germany), an innovative digital post-processing technique, already described for the

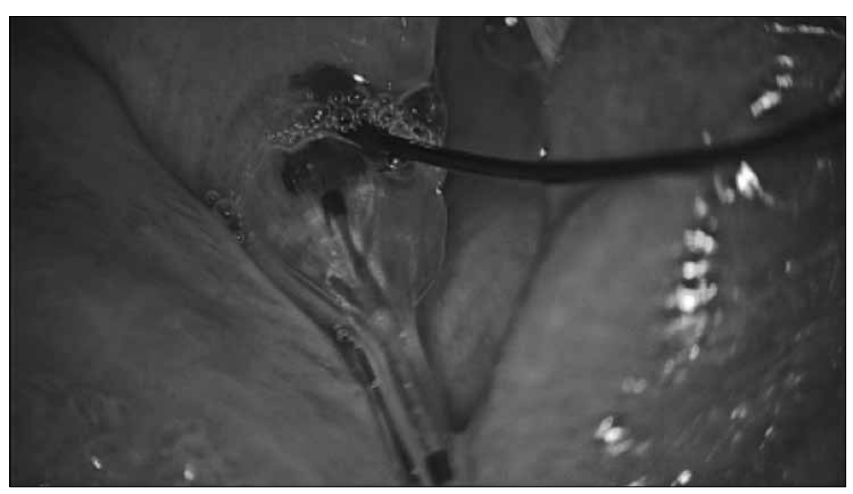

Fig. 2. Balloon dilatation of Wharton's duct. 
evaluation of mucosal precancerous lesions ${ }^{16}$, that emphasises specific colour renderings through the spectral separation of the spectral light information obtained within the camera console and enhances the appearance of recorded images by adapted colour processing algorithms, using five different defined modalities of amplifications of the images (Clara, Chroma, Clara + Chroma, Spectra A, Spectra B).

Stents are available in different shapes, lengths, diameters and materials. In the present series, at the end of the procedure, the terminal part of a suction catheter or, more recently, a salivary stent with a diameter of $1.68 \mathrm{~mm}$ (Schaitkin salivary duct cannula, Hood ${ }^{\circledR}$, U.S.A.) was inserted into the duct to avoid strictures. The stent was sutured with 5/0 Prolene, and maintained for 2 weeks. Stents can be useful in the prevention of restenosis after the dilatation of ductal strictures or to avoid a papillary stenosis and secondary iatrogenic obstruction after papillotomy. Stent placements may also be helpful in the regeneration of ductal defects and in keeping a wide luminal diameter after the ductal walls are primarily closed from incision ${ }^{17}$.

External facial nerve dissection, when indicated during minimally invasive external approaches, was always performed by coupling the intraoperative microscope with the NIM (Medtronic NIM Response ${ }^{\circledR} 3.0$ - 4 channels). Typical parameters used at our institution are: stimulus intensity of 0.5-0.7 $\mathrm{mA}$, duration of the stimulus of $100 \mathrm{microsec}$, rate of stimulus of 4 bursts and event threshold of $100 \mu \mathrm{V}$.

All patients were given antibiotics for 7 days postoperatively and reviewed 2 weeks postoperatively at the time of the removal of the stent, and were then followed up for a minimum of 3 months.

The literature review was based on the MEDLINE search, using "sialendoscopy", "endoscopy", "salivary glands", "lithiasis", "lithotripsy", and "holmium:YAG laser" as keywords.

\section{Results}

Forty-eight patients treated at the University Hospital of Cagliari were included in the present study (26 females and 22 males; median age 45.3; range of 8-83 years) with a unilateral $(n=40)$ or bilateral $(n=8)$ pathology; a total of 56 major salivary glands were treated endoscopically with curative intent ( 22 submandibular glands and 34 parotids), for a total of 68 procedures performed.

Five patients underwent bilateral sialendoscopy for juvenile recurrent parotitis. Ten patients were treated for non-lithiasic obstructive disease: 4 patients for stenosis (1 in the submandibular gland and 3 in the parotid gland), 5 patients for chronic sialadenitis ( 2 in the submandibular gland and 1 in the parotid gland, bilateral chronic obstructive parotitis in 1 case, and 1 patient presented with a submandibular and contralateral parotid sialadenitis), and 1 patient underwent combined approach to the parotid, that allowed for the precise diagnosis of sialocele and subsequent definitive treatment in form of total parotidectomy. In 33 patients $(68.75 \%)$, the obstruction was caused by stones ( 1 patient presented a bilateral parotid lithiasis); in 7 cases the lithiasis was associated with a simultaneous cause (kinking in 3 cases and stricture in 4 cases). In 11 patients treatment was an endoscopic surgery without the use of laser ( 7 in the submandibular gland and 4 in the parotid gland), 20 patients underwent holmium:YAG laser sialendoscopy (11 in the submandibular gland, 8 in the parotid gland, and 1 in the parotid gland bilaterally), and 2 patients underwent the stone removal through a combined approach on the parotid gland.

A single procedure was not effective in 12 cases. In 4 patients a second endoscopic treatment was effective to resolve a recurrence of parotid gland sialadenitis ( 2 patients developed recurrence of symptoms, which were immediately resolved by endoscopic dilatation, 1 patient presented with chronic sialadenitis after successful removal of salivary stones through laser sialendoscopy, requiring sialendoscopic washing of the salivary ducts and 1 patient resolved the pathology after a second holmium:YAG laser sialendoscopy associated with the balloon dilatation for a residual stone previously missing), while 8 patients underwent definitive traditional open neck sialectomy ( 5 submandibular sialectomies and 3 total parotidectomies): two patients with submandibular (1 case) and parotid (1 case) sialolithiasis treated during the early series, when the laser lithotripsy was not available, underwent delayed sialectomy after sialendoscopy that showed the unfeasibility of the endoscopic removal of a salivary stone. Two submandibular sialectomies were performed in patients with lithiasis after holmium:YAG laser sialendoscopy that showed the unfeasibility of the endoscopic procedure during the same general anaesthesia. Two submandibular sialectomies were performed during the same general anaesthesia after an endoscopic procedure without holmium:YAG laser that showed the unfeasibility of the conservative approach (one lithiasis associated with severe chronic inflammation, and one fibrotic stenosis). One patient, who had his parotid stone removed successfully after laser lithotripsy, developed intractable stenosis that required parotidectomy, and 1 patient needed a total parotidectomy after the diagnosis of obstructive sialocele performed through a combined approach procedure. Five patients who underwent sialendoscopy were treated under local anaesthesia. We had one perforation of the duct due to the high-pressure saline washing that required sialectomy (submandibular). Clinical data of the entire cohort of patients are summarised in Table I. Number and size of stones according to definitive treatment are detailed in Table II. Results of procedures done from January 2009 and December 2013 at the Ear, Nose and Throat Unit of Sant'Orsola Hospital of Bologna as already published by Farneti et al. ${ }^{13}$ are summarised in Table III. 
Table I. Cohort of patients treated at the University Hospital of Cagliari.

\begin{tabular}{|c|c|c|c|c|c|c|c|c|c|c|c|}
\hline Case & Sex & Age & Gland & $\begin{array}{l}\text { No. } \\
\text { stones }\end{array}$ & Size & Laser & Stent & $\begin{array}{l}\text { Resolution } \\
\text { of symptoms }\end{array}$ & Baloon & Recurrence & Further treatment \\
\hline 1 & M & 58 & SM & l & l & - & - & Y & Y & N & - \\
\hline 2 & M & 53 & SM & 1 & 10 & - & - & $\mathrm{N}$ & - & - & Delayed sialectomy \\
\hline 3 & M & 40 & $P$ & 1 & 10 & - & - & $\mathrm{N}$ & - & - & Delayed sialectomy \\
\hline 4 & $\mathrm{~F}$ & 8 & $P$ & I & I & - & - & Y & - & Y & Washing + dilatation \\
\hline 5 & $\mathrm{~F}$ & 83 & SM & 1 & 4 & - & - & Y & - & $\mathrm{N}$ & - \\
\hline 6 & $\mathrm{~F}$ & 26 & SM & 1 & 4 & - & - & Y & - & $\mathrm{N}$ & - \\
\hline 7 & M & 44 & SM & 1 & 7 & Y & Y & Y & - & $\mathrm{N}$ & - \\
\hline 8 & $\mathrm{~F}$ & 34 & SM & 1 & 8 & Y & - & Y & - & $\mathrm{N}$ & - \\
\hline 9 & $F$ & 40 & SM & 1 & 6 & Y & - & Y & - & $\mathrm{N}$ & - \\
\hline 10 & $F$ & 38 & SM & 1 & 10 & Y & - & Y & - & $\mathrm{N}$ & - \\
\hline 11 & $\mathrm{~F}$ & 67 & $P$ & 1 & 11 & Y & Y & Y & - & $\mathrm{N}$ & - \\
\hline $12^{*}$ & $F$ & 58 & $P$ & 3 & $4-5-7$ & Y & Y & $Y$ & - & Y & Washing \\
\hline 13 & $\mathrm{~F}$ & 30 & P Bil. & I & I & - & - & Y & - & $\mathrm{N}$ & - \\
\hline 14 & M & 51 & $P$ & 1 & 7 & Y & - & Y & Y & Y & $\begin{array}{l}\text { Delayed sialectomy for } \\
\text { long-term stricture }\end{array}$ \\
\hline 15 & M & 78 & P Bil. & $1+1$ & $4-8.5$ & Y & Y & Y & - & Y & Yag:Holmium + dilatation \\
\hline 16 & M & 12 & P Bil. & l & l & - & - & Y & Y & $\mathrm{N}$ & - \\
\hline 17 & M & 62 & SM & 1 & 3.5 & - & Y & Y & Y & $\mathrm{N}$ & - \\
\hline $18^{\star \star}$ & M & 69 & SM & 1 & 15 & Y & - & - & - & - & Sialectomy \\
\hline 19 & $\mathrm{~F}$ & 19 & $P$ & 1 & 4 & Y & Y & Y & - & $\mathrm{N}$ & - \\
\hline 20 & M & 40 & SM & 1 & 14 & Y & Y & Y & Y & $\mathrm{N}$ & - \\
\hline 21 & $\mathrm{~F}$ & 65 & $P$ & 2 & $1-4$ & Y & Y & Y & Y & $\mathrm{N}$ & - \\
\hline $22^{\star \star}$ & M & 45 & SM & l & - & - & - & - & Y & - & Sialectomy \\
\hline 23 & M & 52 & $P$ & 1 & l & - & - & Y & Y & $\mathrm{N}$ & - \\
\hline 24 & $\mathrm{~F}$ & 58 & $P$ & l & / & - & - & Y & Y & Y & Washing + dilatation \\
\hline $25^{\star \star}$ & M & 26 & SM & 1 & $>10$ & - & - & - & - & - & Sialectomy \\
\hline 26 & M & 37 & $P$ & 1 & 1 & - & - & Y & Y & $\mathrm{N}$ & - \\
\hline 27 & M & 38 & SM & 2 & $8-6$ & Y & Y & Y & - & $\mathrm{N}$ & - \\
\hline 28 & M & 37 & $P$ & 1 & 6 & Y & Y & Y & - & $\mathrm{N}$ & - \\
\hline 29 & $\mathrm{~F}$ & 27 & $P$ & 2 & $3-5$ & - & - & Y & - & $\mathrm{N}$ & - \\
\hline 30 & $\mathrm{~F}$ & 19 & SM & 2 & $1-4.5$ & - & Y & Y & - & $\mathrm{N}$ & - \\
\hline 31 & $\mathrm{~F}$ & 9 & P Bil. & I & I & - & - & $Y$ & - & $\mathrm{N}$ & - \\
\hline 32 & $\mathrm{M}$ & 39 & SM & 1 & 8 & Y & $Y$ & Y & - & $\mathrm{N}$ & - \\
\hline $33^{* *}$ & $\mathrm{~F}$ & 53 & SM & 1 & 15 & Y & - & - & - & - & $\begin{array}{l}\text { Sialectomy after ductal } \\
\text { perforation }\end{array}$ \\
\hline 34 & $F$ & 42 & $P$ & 1 & 10 & $Y$ & $Y$ & $Y$ & - & $\mathrm{N}$ & - \\
\hline 35 & $F$ & 63 & SM & 1 & 9 & - & $Y$ & Y & - & $\mathrm{N}$ & - \\
\hline 36 & $F$ & 63 & $P+S M$ & 1 & 1 & - & - & $Y$ & - & $\mathrm{N}$ & - \\
\hline 37 & $F$ & 9 & P Bil. & I & I & - & - & $Y$ & $Y$ & $\mathrm{~N}$ & - \\
\hline 38 & $\mathrm{M}$ & 10 & P Bil. & 1 & I & - & - & $Y$ & - & $\mathrm{N}$ & - \\
\hline 39 & $M$ & 9 & P Bil. & I & I & - & - & $Y$ & - & $\mathrm{N}$ & - \\
\hline 40 & $F$ & 56 & $P$ & 1 & I & - & - & $Y$ & $Y$ & $\mathrm{~N}$ & - \\
\hline 41 & $\mathrm{~F}$ & 38 & $P$ & 3 & $2-4-4$ & $Y$ & $Y$ & $Y$ & - & $\mathrm{N}$ & - \\
\hline 42 & $\mathrm{M}$ & 42 & SM & 1 & 8 & Y & $Y$ & $Y$ & - & $\mathrm{N}$ & - \\
\hline $43^{\star \star \star}$ & $M$ & 59 & $P$ & 1 & 11 & - & $Y$ & $Y$ & - & $\mathrm{N}$ & - \\
\hline 44 & $F$ & 30 & SM & 1 & 4 & Y & $Y$ & $Y$ & - & $\mathrm{N}$ & - \\
\hline 45 & $\mathrm{~F}$ & 76 & $P$ & I & I & - & $Y$ & $Y$ & $Y$ & $\mathrm{~N}$ & - \\
\hline $46^{\star \star \star}$ & $M$ & 40 & P & 1 & 8 & - & - & $Y$ & - & $\mathrm{N}$ & - \\
\hline 47 & $\mathrm{~F}$ & 46 & SM & 3 & $1.8-1.8-1.8$ & - & - & Y & - & $\mathrm{N}$ & - \\
\hline $48^{\star \star \star}$ & $\mathrm{F}$ & 48 & $P$ & I & I & - & - & $\mathrm{N}$ & - & - & Delayed sialectomy \\
\hline \multicolumn{12}{|c|}{$\begin{array}{l}{ }^{*} \text { Case } n .12 \text { had } 3 \text { stones but only the stone of } 7 \mathrm{~mm} \text { was removed after fragmentation. }{ }^{* *} \text { The sialectomy was performed after the endoscopic procedure during the same } \\
\text { anaesthesia. }{ }^{* * *} \text { Patients treated through a combined approach. }\end{array}$} \\
\hline 106 & & & & & & & & & & & \\
\hline
\end{tabular}


Table II. Stone dimensions.

\begin{tabular}{lccc} 
Groups & No. of stones & Mean & Range \\
Stones removed trough submandibular endoscopic surgery without laser & 9 & $3.5 \mathrm{~mm}$ & $1-9 \mathrm{~mm}$ \\
Stones removed through submandibular holmium:YAG laser sialendoscopy & 10 & $7.9 \mathrm{~mm}$ & $4-14 \mathrm{~mm}$ \\
Stones definitively removed through submandibular sialectomy & 4 & $2.5 \mathrm{~mm}$ & $10-15 \mathrm{~mm}$ \\
Stones removed trough parotid endoscopic surgery without laser & 5 & $3.6 \mathrm{~mm}$ & $1-5 \mathrm{~mm}$ \\
Stones removed through parotid holmium:YAG laser sialendoscopy & 13 & $5.6 \mathrm{~mm}$ & $1-11 \mathrm{~mm}$ \\
Stones removed through combined approach to the parotid gland & 2 & $9.5 \mathrm{~mm}$ & $8-11 \mathrm{~mm}$ \\
Stones definitively removed through total parotidectomy & 1 & $10 \mathrm{~mm}$ & $10 \mathrm{~mm}$ \\
\hline
\end{tabular}

Table III. Results of procedures done from January 2009 and December 2013 at the Ear, Nose and Throat Unit of Sant'Orsola Hospital of Bologna. SM = submandibular; $\mathrm{GA}=$ general anesthesia; $\mathrm{LA}=$ local anaesthesia; $\mathrm{CN}=$ cranial nerve; $\mathrm{RJP}=$ recurrent juvenile parotitis; $N / A=$ data not available.

\begin{tabular}{|c|c|c|c|c|c|c|c|c|}
\hline Procedures & Patients & $\begin{array}{l}\text { Parotid/ } \\
\text { SM }\end{array}$ & Complications & $\begin{array}{l}\text { SM } \\
\text { resection }\end{array}$ & GA/LA & Pathologies & $\begin{array}{l}\text { Stone } \\
\text { Removal }\end{array}$ & Results \\
\hline 141 & 118 & $74 / 67$ & $\begin{array}{l}3 \text { infections } \\
2 \text { basket wire breaking } \\
1 \text { transient paresis of VII CN } \\
1 \text { lingual paresthesia } \\
1 \text { distal stenosis }\end{array}$ & $\begin{array}{l}3 \\
\text { of } 130 \text { glands } \\
\text { treated }\end{array}$ & $40 / 101$ & $\begin{array}{l}62 \text { Lithiasis } \\
40 \text { Diagnostic } \\
26 \text { Stenosis } \\
6 \text { RJP } \\
6 \text { Mucous plug } \\
1 \text { Polyp }\end{array}$ & $\begin{array}{l}26 \text { Basket } \\
27 \text { Combined } \\
\text { technique } \\
9 \text { Not removed at } \\
\text { first attempt }\end{array}$ & $\begin{array}{l}102 \text { Asymptomatic } \\
(72.3 \%) \\
37 \text { Recurrence of } \\
\text { symptoms }(26.3 \%) \\
2 \text { N/A data }(1.4 \%)\end{array}$ \\
\hline
\end{tabular}

\section{Discussion}

Sialendoscopic techniques are relatively new and are increasingly used in the management of non-neoplastic diseases of the major salivary glands. Since histopathological studies suggest that salivary glands removed for sialolithiasis have normal glandular architecture ${ }^{18}$, organ preservation should be the first goal of every treatment ${ }^{10}$, reducing the morbidity of the open surgery.

At present, US represents an excellent first-level diagnostic technique in preoperative work-up. However, Deenadayal et al. observed that US is a good modality with high sensitivity for lithiasis, but it has low sensitivity in nonlithiasic obstructions ${ }^{19}$. In our series, the majority of patients were investigated through CT to exclude or confirm the presence of stones and to assess their precise dimensions and number. Furthermore, CT is routinely requested by the surgeon to precisely locate the stone.

Sialendoscopy alone is nowadays part of the main diagnostic tools, improving the sensitivity of traditional imaging approaches ${ }^{19}$. It offers an additional advantage due to its therapeutic action in dilating the salivary ducts with high-pressure saline solution, washing and, consequently, treating moderate stenosis and strictures. Sialendoscopy is indicated for diagnosis of sialolithiasis, stenosis, foreign bodies, polyps, recurrent sialadenitis and sialadenosis ${ }^{15}$. The basic surgical procedure is divided in three steps: location of the papilla and introduction of the sialendoscope, diagnosis (from main duct to third or fourth salivary division branches) and therapeutic steps ${ }^{20}$.

The identification of the papilla can be difficult. Therefore, magnifying loupes or a microscope can be helpful. The visibility of the papilla can be enhanced with the massage of the gland with one hand until the leak of saliva makes it more visible; this technique can be improved by using sialagogues like ascorbic acid or lemon juice ${ }^{21}$. Lidocaine hydrochloride $10 \mathrm{~g} / 100 \mathrm{ml}$ spray should be used as a local anaesthetic. The natural papilla diameter is about 0.5 $\mathrm{mm}^{22}$, and its dilation is thus necessary to allow the access of the endoscope through the duct, and can be performed with different methods. The "classic technique" is realised by dilating the papilla with progressive salivary probes $^{23}$. A conic dilatator can be useful to maximise the dilatation of the ducts at the end of the procedure. It can also be used at the first instance when the papilla is easily detectable to avoid lesions of the duct, which are more frequent with progressive salivary probes. The "guided puncture technique" begins with the introduction of the probe of smaller diameter 0000 that is successively replaced from a guide in titanium of same diameter (principle of Seldinger) ${ }^{24}$. A conical dilator is introduced on this guide to expand the papilla progressively. The dilatator is then removed and the endoscope is introduced using the guide thorough the working channel. The guide is removed when a ductal image is correctly obtained. When the papilla is not easily localised, a "surgical" less conservative technique can be performed as described by Nahlieli ${ }^{25}$. An incision is made at the level of the oral pelvis parallel to the axis of the duct, looking for it carefully on the medial aspect of the sublingual gland. Once detected the duct, it is necessary to open it for $1 \mathrm{~mm}$ to allow insertion of the endoscope without losing pressure during irrigation. This technique is reserved when an atraumatic approach is not possible for papillary hypertrophy, papillary stenosis or extremely small ductal orifices. The as- 
sistant's role is fundamental: it is necessary to provide a correct visualisation of the surgical field and to support the surgeon in managing operative instruments.

After the introduction of the tip of the endoscope, the ductal system is dilated by continuous irrigation with $0.9 \%$ saline solution using 20 or $50 \mathrm{~mL}$ syringes to avoid the collapse of the duct ${ }^{26}$. When the procedure is performed under local anaesthetic, irrigation should start using $2 \%$ lidocaine hydrochloride. Additionally, irrigation helps to remove debris, such as fibrin or small stone fragments. The diagnostic step permits exploration of the entire ductal system from the main duct to the secondary and third/fourth branches. The duct must be pulled with no traumatic peripapillary traction to make the duct assume a rectilinear shape that facilitates its exploration ${ }^{20}$. This step can be best performed using small diagnostic $0.8 \mathrm{~mm}$ endoscopes that can easily follow the duct and the smaller branches, and show possible pathological findings (i.e. stones, stenosis, ductal inflammation). The main difficulties found during the exploration of specific tracts of the salivary tracts include: at the "comma area" of Wharton's duct, where the duct turns inferiorly at the posterior border of the mylohyoid muscle, in the area posterior to the curvature of the Stensen's duct (around the masseter muscle), and when the duct passes through the buccinator muscle ${ }^{25}$.

Sialendoscopy can be both diagnostic and therapeutic in the same procedure, while other imaging techniques, even if minimally invasive, can be useful only for diagnosis ${ }^{27}$. The therapeutic step of sialedoscopy can target the cause of the obstructive sialadenitis. Sialendoscopy alone or with mucous plug removal, is generally enough to resolve juvenile recurrent parotitis, as observed in the literature and in our series (5 cases) ${ }^{28}{ }^{29}$. Symptoms of chronic sialadenitis, Sjögren's syndrome and radiation-induced sialadenitis (either after external radiation therapy or as a sequela of radioactive iodine treatment for thyroid carcinoma) are generally improved through washing and dilatation ${ }^{3031}$.

Management of stenosis or other anatomic malformations often requires endo-luminal dilation, which can be easily achieved with high-pressure balloons, microdrills, forceps, or simply with a larger endoscope ${ }^{27}$. Sionis et al. ${ }^{32}$ showed that non-compliant balloon offers steady dilatation of the duct with only minor disruption of the epithelium, this confirmed histologically after dilatation of the Wharton's duct on 4 cadavers. In this experimental study, the use of a 6-mm non-compliant balloon was feasible and safe in a conservative approach to the Wharton's duct without risking the rupture of the wall. In our series, endoscopic procedures for non-lithiasic diseases were effective in $86.7 \%$ of patients $(13 / 15)$, and $90.1 \%$ of salivary glands (20/22): 1 patient underwent submandibular sialectomy for a severe stricture of the Wharton's duct, and 1 patient needed definitive sialectomy after diagnosis of parotid sialocele during an endoscopic assisted procedure.
In literature sialolithiasis is the most frequent cause of chronic obstructive sialadenitis ${ }^{1}$ (in our series, $68.75 \%$ of patients were treated for salivary stones). The removal of distal stones (proximal to the papilla) of the submandibular gland is possible through a minimal-invasive non-endoscopic intraoral approach with no major complications. The trans-oral removal of the stone could be coupled with the operating microscope, and the lithiasis can be retrieved through the papilla after dilatation or by incising the duct at the level of the stone. The role of the endoscopic approach to lithiasis of major salivary glands has been detailed in a recent Italian consensus by Gallo et al. ${ }^{15}$.

Distal duct/papilla. If there are mobile ductal stones $<5$ $\mathrm{mm}$, sialendoscopy with basket retrieval may be the first attempt, and papillotomy may be necessary; if the stones are impacted, transoral duct slitting is generally performed before interventional sialendoscopy.

Proximal duct/hilum. In case of small, mobile stones $<5$ $\mathrm{mm}$ attempting to remove the stone with a wire basket or grasping forceps is indicated; if stones are $>7 \mathrm{~mm}$ and palpable, a transoral duct incision or combined endoscopic-guided removal can be performed if fragmentation tools are not available.

Intraparenchymal. Mobile stones $<7 \mathrm{~mm}$ can be removed via interventional sialendoscopy if they are impacted; stones $>7 \mathrm{~mm}$ up to $10 \mathrm{~mm}$ can be fragmented allowing endoscopic removal.

When a ductal stenosis is associated with the lithiasis, it is also possible to dilate a stenotic duct by using an expandable balloon catheter, as observed in 5 patients of our series.

Stones less than $5 \mathrm{~mm}$ with regular contour (round or oval) and with its major axis perpendicular to main duct are the most simple to extract: simply using the basket that is placed behind the stone, opening it (entrapping the stone) and then gently retracting it (Fig. 3).

The classic main limitation for sialendoscopy in sialolithiasis is the size of the stone, but the different techniques described for stone fragmentation (external lithotripsy, electrohydraulic, piezoelectric, electromagnetic and pneumoblastic lithotripsy, holmium:YAG lithotripsy) 9 33-36 allow to treat even larger stones through a conservative endoscopic approach. Sialolithotripsy is a non-invasive method of fragmenting salivary stones into smaller portions to favour their flushing out from the salivary duct system spontaneously or after salivation induced by citric acid or other sialogogues ${ }^{2}$. The shock-waves may be generated extra-corporeal using piezoelectric and electromagnetic techniques or intracorporeal using laser or pneumatic endoscopic devices. The main limitation of extracorporeal lithotripsy is that it often leaves stone fragments inside the duct system ${ }^{18}$. Piezoelectric technique exploits the pressure wave produced in water by the expansion of crystals due to the application of voltage. The crystals are placed on a concave disk that converges the wave on a $3 \mathrm{~mm}$ area 


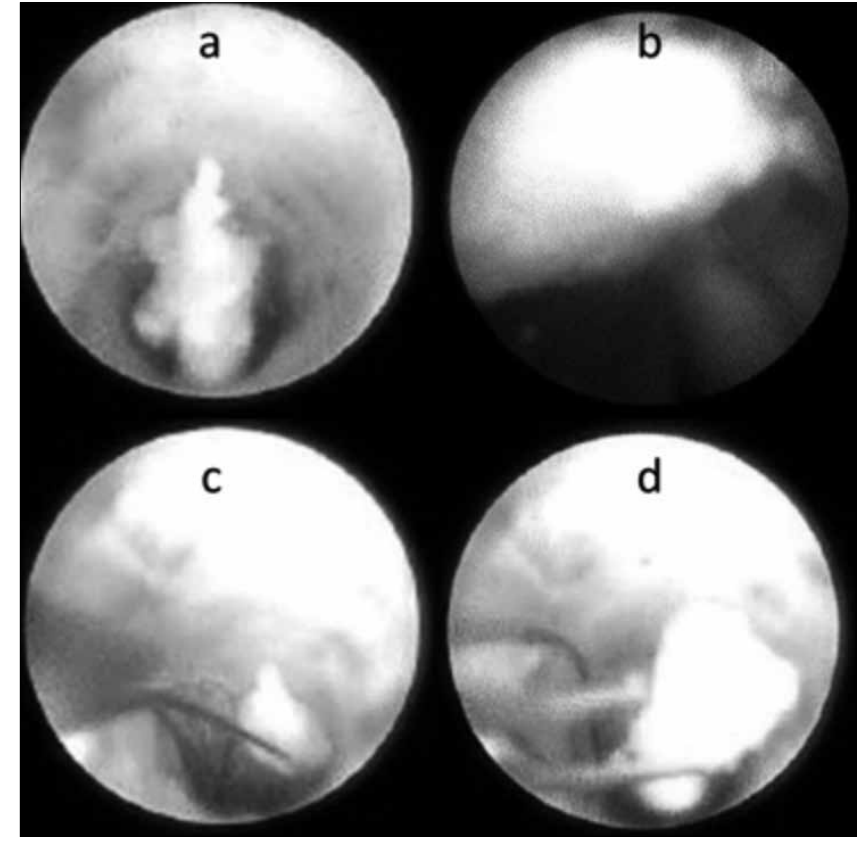

Fig. 3. Stone removal with basket. a: Stone in the salivary duct. b: Positioning of the basket behind stone. c: Opening of the basket. d: Entrapment of the stone.

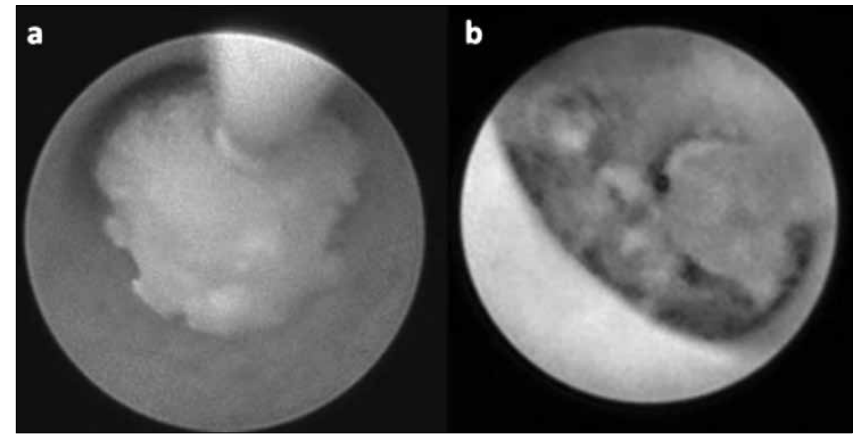

Fig. 4. Endoscopic view of a parotid stone before (a) and after (b) holmium:YAG laser fragmentation. to a depth of $11 \mathrm{~mm}^{37}$. In the electromagnetic technique, the ultrasound-guided shock-wave is generated by a smalldiameter, cylindrical, electromagnetic source, and focuses on the salivary stones by means of a parabolic reflector within the cushion. The pulse frequency of the wave may vary from 0.5 to $2 \mathrm{~Hz}$ and no more than 4000 shock-waves may be administered per session. Continuous sonographic monitoring allows direct visualisation of the degree of fragmentation during treatment and avoids lesions to the surrounding tissues ${ }^{38}$. Intracorporeal laser lithotripsy includes different devices distinguished according to laser or pneumatic energy. Different lasers with a large variety of diameters and connectors are available from multiple manufacturers and only bare fibres are used. Fibres are fragile and should not be angularly bent ${ }^{14}$. A holmium:YAG laser is compatible with a conventional silica fibre, making it suitable for both endoscopic and percutaneous use. A pulsed dye laser has shown efficacy and low morbidity, as the high energy delivered is not absorbed by tissues. Unfortunately, its high cost and specificity for salivary stones make it unaffordable for a single referral centre ${ }^{39}$. An erbium laser emits a wavelength that coincides with the highest water absorption peak, thus providing this laser with unique characteristics in a variety of surgical applications. Hollow metal wave guides optimised for an Er:YAG laser were end-sealed with a polished sapphire rod of 0.63 $\mathrm{mm}$, designed to adapt to the laser and the endoscope. Raif et al. described 5 stones fully fragmented and 7 prepared for extraction by mini-forceps out of 21 stones treated with this technique ${ }^{40}$. The thulium YAG laser was demonstrated to be effective in stone fragmentation with a low rate of complications $(12.7 \%$ ductal perforations reported by Durbec et al.) ${ }^{41}$. A pneumatic lithotripter permits the fragmentation of the stone through a $\mathrm{CO} 2$ gas-driven system. The mechanical shock is transmitted through the tip of the instrument probe directly to the stone and is atraumatic to the surrounding tissues.

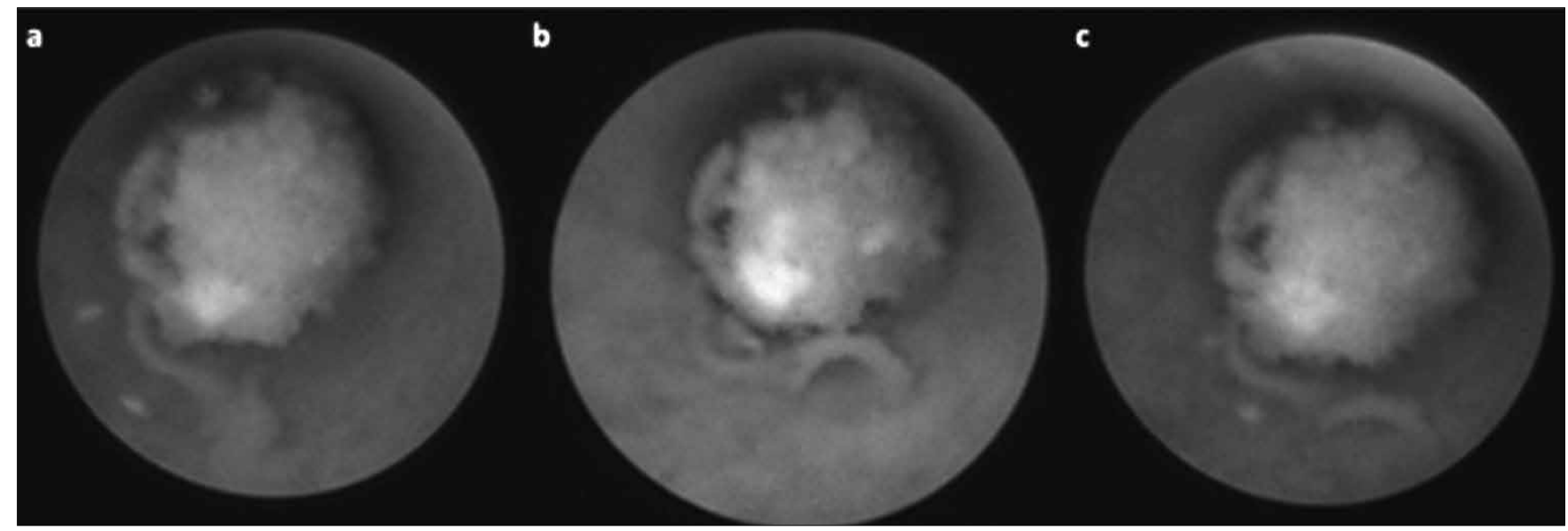

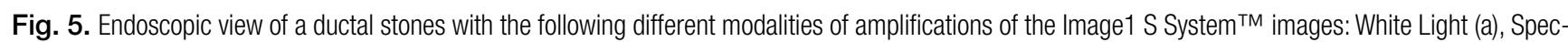
$\operatorname{tra} A$ (b), Spectra B (c). 
In the present series, endoscopic lithotripsy was always performed with a holmium:YAG laser (20 patients, 21 salivary glands) (Fig. 4). This tool allowed to fragment and remove larger stones with minimal complications and to extract the stones after a single procedure in 16 of 21 cases $(76.2 \%)$, a second endoscopic procedure was necessary to resolve the pathology in 2 cases $(9.5 \%)$ : in 1 case endoscopic washing was necessary to remove mucous plugs, while a second laser holmium:YAG lithotripsy was necessary in 1 case to remove a residual stone. As a consequence, only 3 of 21 salivary glands treated with sialendoscopic removal after lithotripsy $(14.3 \%)$ required a definitive sialectomy. Parotid stones treated by holmium:YAG laser lithotripsy (mean delivered energy of $0.11 \mathrm{~kJ}$ ) were between 1 and $11 \mathrm{~mm}$ in size (mean $5.6 \mathrm{~mm}$ ), larger than parotid stones removed through endoscopy without fragmentation (1-5 $\mathrm{mm}$ in size, mean $3.6 \mathrm{~mm}$ ). In our series we did not experience any perforation of the ductal system due to laser. In our experience, sialoendoscopy was also coupled with Image1 S Systems to allow better discrimination between stones and the wall of the duct (Fig. 5). After all therapeutic procedures, a final exploration of all the branches of the salivary duct is appropriate to detect any other associated pathologies.

Sialendoscopy can be done under local or general anaesthesia as a one-day procedure, and preserves the gland with recovery of function and without risk of damage to nerves, all without an external incision. In the present series, most cases were treated under general anaesthesia since endoscopic lithotripsy can result in a prolonged and painful procedure for the continuous irrigation and dilation of the ductal system, while in the series of Farneti et al. general anaesthesia was used in $28.4 \%$ of cases ${ }^{13}$.

Proximal salivary gland stones with a diameter between 8 and $11 \mathrm{~mm}$ were also managed through a sialendoscope-assisted procedure, a minimal invasive technique for identification and external removal of impacted parotid lithiasis. Identification of the stone is made using a $1.1 \mathrm{~mm}$-sialendoscope and the stone can be removed through a minimal facial-lift skin incision (Fig. 6). After the incision, the duct is identified under microscopic view. Facial nerve branches that can cross the hilum and the duct are identified with the aid of a nerve stimulator with minimal exposure of the wall of the duct, allowing stone extraction and Stensen's duct microsuture (Fig. 7), without complications.

According to the literature, sialendoscopy is an effective procedure in $79-86.4 \%$ of cases ${ }^{42} 43$. Adverse events after sialendoscopy are unusual and not severe ${ }^{10}$. However, the accidental tearing of the ductal wall can potentially lead to extravasation of the irrigation solution and debris during sialendoscopy, with consequent neck swelling, airway obstruction, or deep neck abscesses ${ }^{32}{ }^{10}$. In case of partial success or failure of minimal-invasive procedures, sialectomy still remains a valid option ${ }^{10}$.

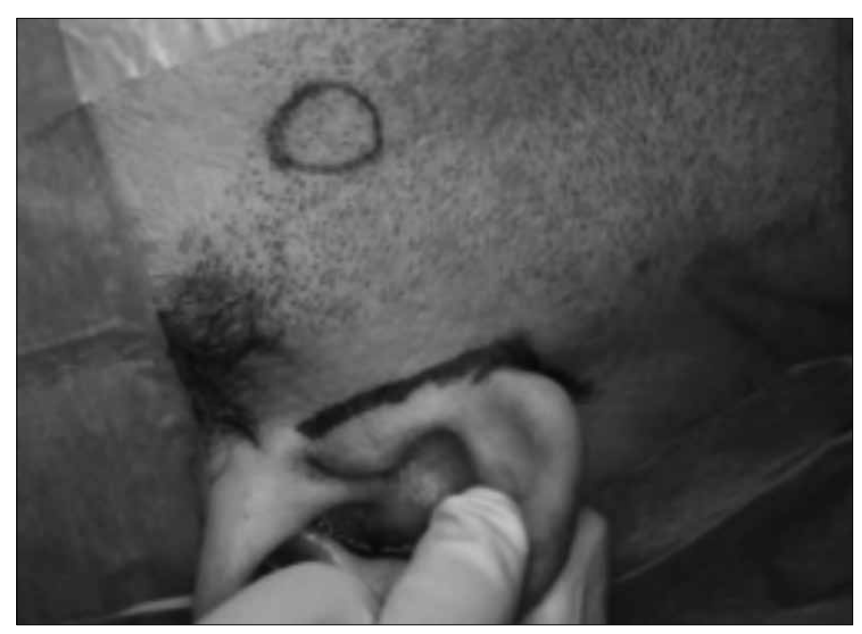

Fig. 6. Minimal facial-lift skin incision for a right parotid stone.

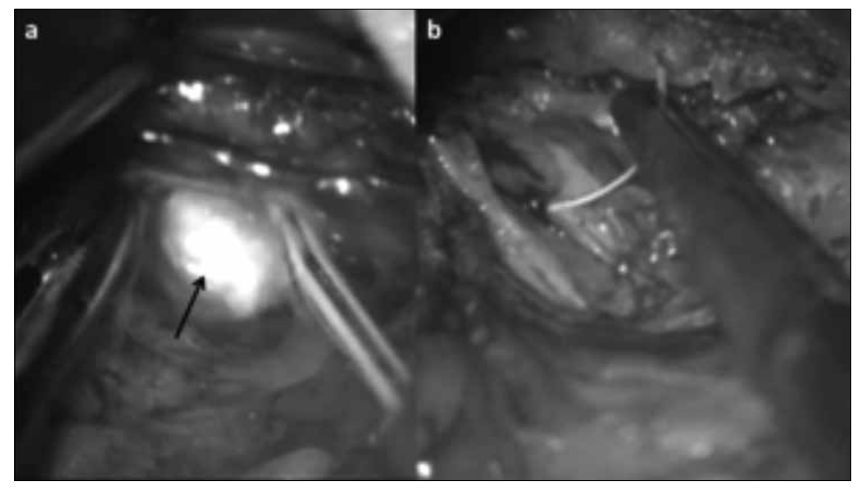

Fig. 7. Parotid stone (arrow) extraction (a) and Stensen's duct suture (b).

\section{Conclusions}

Gland preservation should be considered whenever feasible, especially in patients with parotid gland disease. Sialendoscopy allows for endoscopic visualisation of the ductal system and its development is fundamental for a surgical minimal invasive approach to obstructive sialadenitis, which is a remarkable improvement in otolaryngology and readily available for the benefit of patients. This technique has the great advantage of identifying and removing the most common causes of obstruction in the same procedure. The widespread diffusion of this endoscopic technique has reduced the indications for the traditional open sialectomy (no scar, no risk of facial and lingual nerve injuries). The only contraindication is acute ductal infection, temporary paraesthesia of the lingual or facial nerves, infections, oedema and ductal perforation. Maximum success can only be attained by the reasonable combination of all new minimally invasive techniques.

\section{References}

Bodner L. Salivary gland calculi: diagnostic imaging and surgical management. Compendium 1993;14:572,574-6, 578 passim. 
2 Capaccio P, Torretta S, Ottavian F, et al. Modern management of obstructive salivary diseases. Acta Otorhinolaryngol Ital 2007;27:161-72.

3 Berini-Aytes L, Gay-Escoda C. Morbidity associated with removal of the submandibular gland. J Craniomaxillofac Surg 1992;20:216-9.

4 Moeller K, Esser D, Boeger D, et al. Parotidectomy and submandibulectomy for benign diseases in Thuringia, Germany: a population-based study on epidemiology and outcome. Eur Arch Otorhinolaryngol 2013;270:1149-55.

5 McGurk M, Brown J. Alternatives for the treatment of salivary duct obstruction. Otolaryngol Clin North Am 2009;42:1073-85.

6 Katz P. New method of examination of the salivary glands: the fiberscope. Inf Dent 1990;72:785-6.

7 Katz P. Endoscopy of the salivary glands. Ann Radiol 1991;34:110-3

8 Marchal F, Dulguerov P, Lehmann W. Interventional sialendoscopy. N Engl J Med 1999;341:1242-3.

9 Sionis S, Caria RA, Trucas M, et al. Sialendoscopy with and without holmium:YAG laser-assisted lithotripsy in the management of obstructive sialadenitis of major salivary glands. Br J Oral Maxillofac Surg 2014;52:58-62.

10 Atienza G, López-Cedrún JL. Management of obstructive salivary disorders by sialendoscopy: a systematic review. $\mathrm{Br}$ J Oral Maxillofac Surg 2015;53:507-19.

11 Marchal F, Dulguerov P. Sialolithiasis management: the state of the art. Arch Otolaryngol Head Neck Surg 2003;129:951-6.

12 Sun YT, Lee KS, Hung SH, et al. Sialendoscopy with holmium:YAG laser treatment for multiple large sialolithiases of the Wharton duct: a case report and literature review. J Oral Maxillofac Surg 2014;72:2491-6.

13 Farneti $\mathrm{P}$, Macrì G, Gramellini $\mathrm{G}$, et al. Learning curve in diagnostic and interventional sialendoscopy for obstructive salivary diseases. Acta Otorhinolaryngol Ital 2015;35:325-31.

${ }^{14}$ Geisthoff UW. Technology of sialendoscopy. Otolaryngol Clin North Am 2009;42:1001-8.

15 Gallo A, Benazzo M, Capaccio P, et al. Sialendoscopy: state of the art, challenges and further perspectives. Round Table, $101^{\text {st }}$ SIO National Congress, Catania 2014. Acta Otorhinolaryngol Ital 2015;35:217-33.

16 Carta F, Sionis S, Cocco D, et al. Enhanced contact endoscopy for the assessment of the neoangiogenetic changes in precancerous and cancerous lesions of the oral cavity and oropharynx. Eur Arch Otorhinolaryngol 2016;273:1895-903.

$17 \mathrm{Su}$ CH, Lee KS, Tseng TM, et al. Post-sialendoscopy ductoplasty by salivary stent placements. Eur Arch Otorhinolaryngol 2016;273:189-95.

18 Marchal F, Kurt AM, Dulguerov P, et al. Histopathology of submandibular glands removed for sialolithiasis. Ann Otol Rhinol Laryngol 2001;110:464-9.

19 Deenadayal DS, Bommakanti V. Sialendoscopy: a review of 133 cases. International Journal of Otolaryngology and Head \& Neck Surgery 2016;5:28-33.

20 Lari N, Chossegros C, Thiery G, et al. Sialoendoscopie des glandes salivaires. Rev Stomatol Chir Maxillofac 2008;109:167-71.

${ }^{21}$ Luers JC, Vent J, Beutner D. Methylene blue for easy and safe detection of salivary duct papilla in sialendoscopy. Otolaryngol Head Neck Surg 2008;139:466-7.

${ }^{22}$ Zenk J, Zikarsky B, Hosemann WG, et al. The diameter of the Stenon and Wharton ducts: significance for diagnosis and therapy. HNO 1998;46:980-5.

23 Marchal F, Becker M, Dulguerov P, et al. Interventional sialendoscopy. Laryngoscope 2000;110:318-20.

${ }^{24}$ Chossegros C, Guyot L, Richard O, et al. A technical improvement in sialendoscopy to enter the salivary ducts. Laryngoscope 2006:116;842-4.

25 Nahlieli O, Baruchin AM. Sialendoscopy: three years' experience as a diagnostic and treatment modality. J Oral Maxillofac Surg 1997;55:912-8.

26 Geisthoff UW. Basic sialendosopy techniques. Otolaryngol Clin N Am 2009;42:1029-52.

27 Faure M, Boem A, Taffin C, et al. Diagnostic and interventional sialendoscopy. Rev Stomatol Chir Maxillofac 2005;106:250-2.

28 Canzi P, Occhini A, Pagella F, et al. Sialendoscopy in juvenile recurrent parotitis: a review of the literature. Acta Otorhinolaryngol Ital 2013;33:367-73.

29 Schneider H, Koch M, Künzel J, et al. Juvenile recurrent parotitis: a retrospective comparison of sialendoscopy versus conservative therapy. Laryngoscope 2014;124:451-5.

30 De Luca R, Trodella M, Vicidomini A, et al. Endoscopic management of salivary gland obstructive diseases in patients with Sjögren's syndrome. J Craniomaxillofac Surg 2015;43:1643-9.

31 Kim JW, Han GS, Lee SH, et al. Sialoendoscopic treatment for radioiodine induced sialadenitis. Laryngoscope 2007;117:133-6.

32 Sionis S, Vedele A, Brennan PA, et al. Balloon catheter sialoplasty: a safety and feasibility pilot study. Br J Oral Maxillofac Surg 2013;51:228-30.

33 Iro H, Schneider T, Nitsche N, et al. Extracorporeal piezoelectric lithotripsy of salivary calculi. Initial clinical experiences. HNO 1990;38:251-5.

${ }^{34}$ Reimers M, Vavrina J, Schlegel C. Results after shock wave lithotripsy for salivary gland stones. Schweizerische medizinische Wochenschrift 1999:122S-6S

35 Iro H, Nitsche N, Meier J, et al. Piezoelectric shock wave lithotripsy of salivary gland stones: an in vitro feasibility study. $\mathrm{J}$ Lithotr Stone Dis 1991;3:211-6.

36 Iro H, Benzel W, Gode U, et al. Pneumatische intra-korporale Lithotripsie von Speichelsteinen: in-vitro und tierexperimentelle Untersuchungen. HNO 1995;43:172-6.

37 Iro H, Zenk J, Waldfahrer F, et al. Extracorporeal shockwave lithotripsy of parotid stones: results of a prospective trial. Ann Otol Rhinol Laryngol 1998;107:860-4.

38 Ottaviani F, Capaccio P, Rivolta R, et al. Salivary gland stones: US evaluation in shock wave lithotripsy. Radiology 1997;204:437-41.

39 Martellucci S, Pagliuca G, de Vincentiis M, et al. Ho:Yag laser for sialolithiasis of Wharton's duct. Otolaryngol Head Neck Surg 2013;148:770-4.

${ }^{40}$ Raif J, Vardi M, Nahlieli O, et al. An Er:YAG laser endoscopic fiber delivery system for lithotripsy of salivary stones. Lasers Surg Med 2006;38:580-7. 
${ }^{41}$ Durbec M, Dinkel E, Vigier S, et al. Thulium-YAG laser sialendoscopy for parotid and submandibular sialolithiasis. Lasers Surg Med 2012;44:783-6.

${ }^{42}$ Cordesmeyer R, Winterhoff J, Kauffmann P, et al. Sialendoscopy as a diagnostic and therapeutic option for obstructive diseases of the large salivary glands-a retrospective analysis. Clin Oral Investig 2015;11:1-6.

${ }^{43}$ Meyer A, Delas B, Hibon R, et al. Sialendoscopy: A new diagnostic and therapeutic tool. Eur Ann Otorhinolaryngol Head Neck Dis 2013;130:61-5.

Received: September 15, 2016 - Accepted: December 12, 2016

Address for correspondence: Filippo Carta, Policlinico D. Casula, Department of Otorhinolaryngology, Azienda-Ospedaliero-Universitaria, University of Cagliari, School of Medicine. SS $554 \mathrm{~km}$ 4,500, 09124 Monserrato (CA), Italy. Tel. +39 070 51096411. Email: filippocarta@unica.it, pippocarta@tiscali.it 